\title{
Endoscopic diagnosis and treatment of a giant duodenal lipoma presenting with gastrointestinal bleeding
}

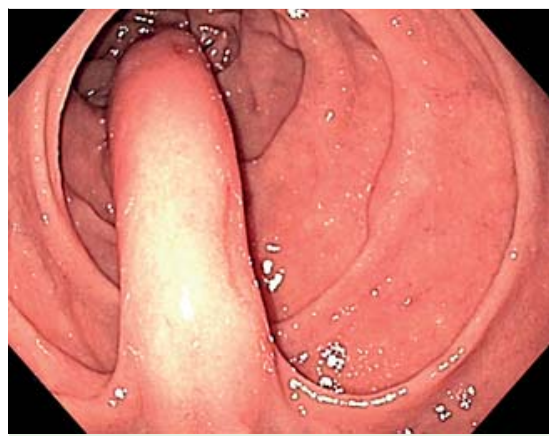

Fig. 1 Endoscopic view of a 3-cm long polypoid lesion with multiple ulcerations in the second part of the duodenum in a 66-year-old man with fatigue and acute upper gastrointestinal bleeding.

A 66-year-old man presented with fatigue and acute upper gastrointestinal bleeding (hemoglobin $92 \mathrm{~g} / \mathrm{L}$ ). He had melena but no signs of hematemesis. Upper gastrointestinal endoscopy revealed a $35 \times 15-\mathrm{mm}$ large polypoid lesion with multiple ulcerations in the second part of the duodenum ( Fig. 1). No biopsy samples were taken due to the risk of bleeding. The diagnosis was unclear and the patient underwent endoscopic ultrasound, which demonstrated a hyperechoic lesion measuring $11 \times 19 \mathrm{~mm}$ in diameter in the submucosa in the duodenal wall with intact muscularis propria ( $\bullet$ Fig.2), suggestive of a lipoma. A subsequent capsule endoscopy excluded distal causes of bleeding in the small intestine. Next, the lesion was removed endoscopically using an endoloop and snare without any complication $(\bullet$ Fig.3). The resected lesion exhibited multiple ulcerated areas ( Fig.4). Histological examination demonstrated a duodenal lipoma with large blood vessels in contact with these ulcerated areas (๑ Fig.5).

Duodenal lipomas are extremely rare and constitute only one in 600 benign tumors of the gastrointestinal tract [1]. Duodenal lipomas are usually asymptomatic but larger ones can, in rare cases, cause abdominal pain, intestinal obstruction, or hemorrhage [2,3]. Symptomatic duodenal lipomas should be removed. The current recommendation is endoscopic excision, unless this is technically difficult and war-

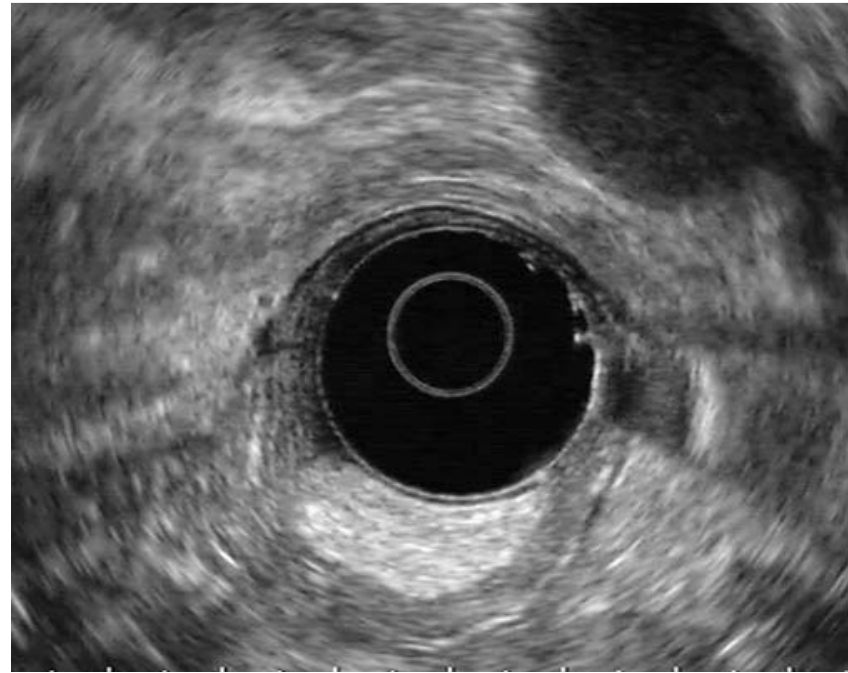

Fig. 2 Endoscopic ultrasound showing a hyperechoic lesion $(11 \times 19 \mathrm{~mm})$ originating from the submucosa in the duodenal wall.
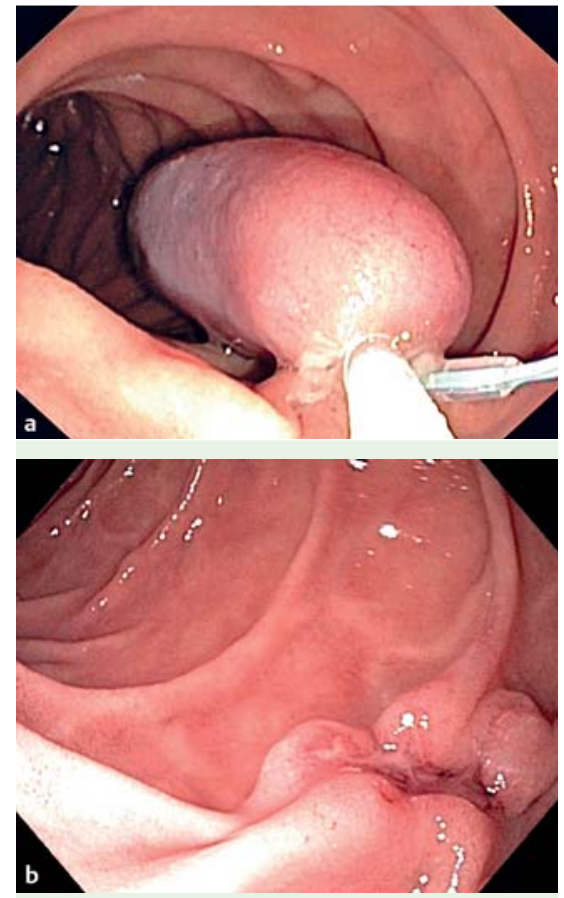

Fig.3 a The lesion was removed using an endoloop and snare (endocut mode effect 2 and forced coagulation effect 2, $30 \mathrm{~W}, \mathrm{VIO} 300 \mathrm{D}$; ERBE Elektromedizin, Tubingen, Germany). b The resection site 24 hours after polypectomy.

rants surgical excision. Nonetheless, this unusual case with a duodenal lipoma causing upper gastrointestinal bleeding underlines the clinical importance of endoscopic ultrasound in the workup of patients with unclear submucosal lesions in the gastrointestinal tract.

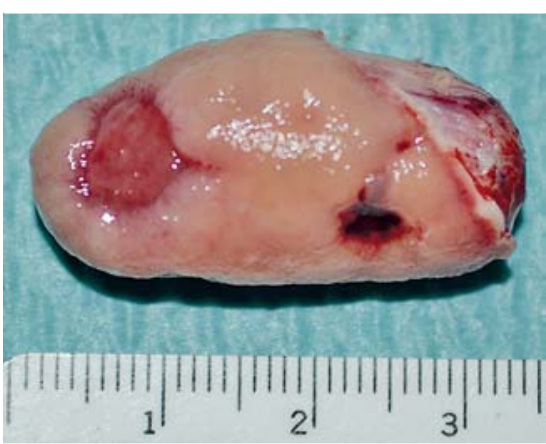

Fig.4 The resected specimen showing multiple ulcerated areas.

Endoscopy_UCTN_Code_CCL_1AB_2AZ

Competing interests: None

\section{Henrik Thorlacius ${ }^{1}$, Håkan Weiber ${ }^{1}$, Otto Ljungberg ${ }^{2}$, Jörgen Nielsen ${ }^{3}$, Ervin Toth ${ }^{3}$}

${ }^{1}$ Section of Surgery, Department of Clinical Sciences, Malmö, Skåne University Hospital, Lund University, Malmö, Sweden

2 Section of Pathology, Department of Clinical Sciences, Malmö, Skåne University Hospital, Lund University, Malmö, Sweden

${ }^{3}$ Section of Gastroenterology, Department of Clinical Sciences, Malmö, Skåne University Hospital, Lund University, Malmö, Sweden 


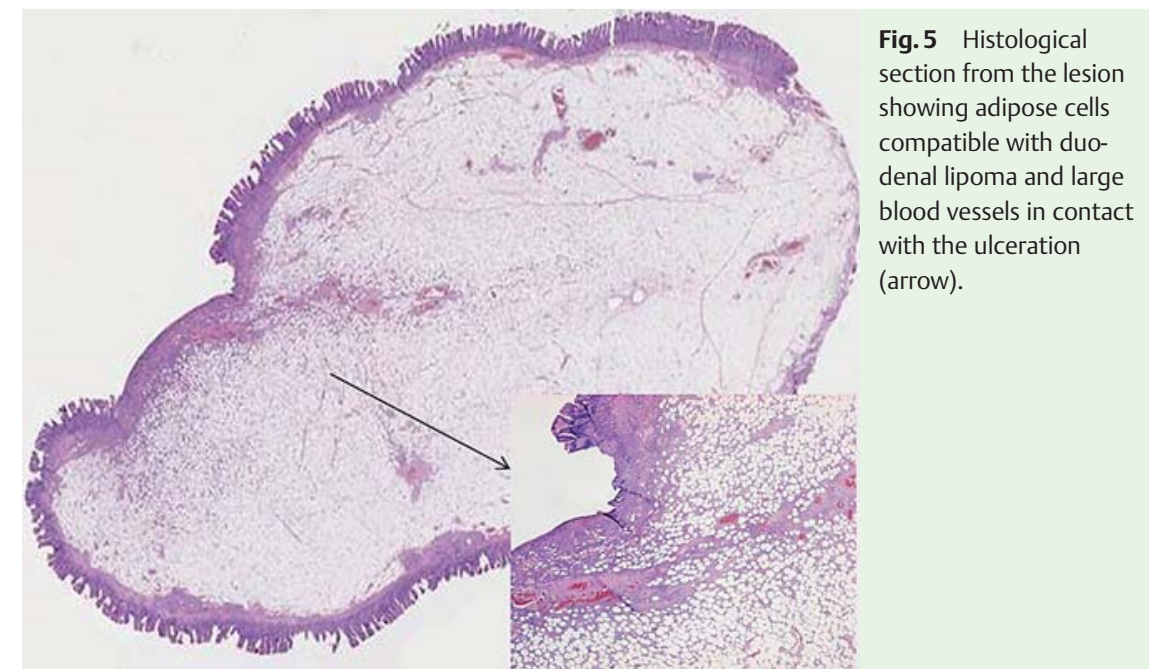

\section{References}

1 Mayo CW, Pagtaluman RJG, Brown DJ. Lipoma of the alimentary tract. Surgery 1963; 53: $598-603$

2 Tung CF, Chow WK, Peng YC et al. Bleeding duodenal lipoma successfully treated with endoscopic polypectomy. Gastrointest Endosc 2001; 54: 116-117

3 Blanchet MC, Arnal E, Paparel P et al. Obstructive duodenal lipoma successfully treated by endoscopic polypectomy. Gastrointest Endosc 2003; 58: 938-939

\section{Bibliography}

DOI http://dx.doi.org/

10.1055/s-0033-1344825

Endoscopy 2013; 45: E385-E386

(c) Georg Thieme Verlag KG

Stuttgart · New York

ISSN 0013-726X

\section{Corresponding author}

\section{Henrik Thorlacius}

Department of Clinical Sciences, Malmö Section of Surgery

Skåne University Hospital

Lund University

S-205 02 Malmö

Sweden

Fax: 46-40-336207

henrik.thorlacius@med.lu.se 